\title{
Intramuscular injection of testosterone undecanoate for the treatment of male hypogonadism: phase I studies
}

\author{
H M Behre, K Abshagen, M Oettel ${ }^{1}$, D Hübler ${ }^{1}$ and E Nieschlag \\ Institute of Reproductive Medicine of the University, Domagkstrasse 11, D-48129 Münster, Germany and ${ }^{1}$ Jenapharm GmbH E Co. KG, \\ Jena, Germany \\ (Correspondence should be addressed to E Nieschlag)
}

\begin{abstract}
Objective: In the search for long-acting testosterone preparations suited for substitution therapy of hypogonadal men, testosterone undecanoate (TU) dissolved in either tea seed oil or castor oil was investigated.

Design: In study I, $1000 \mathrm{mg}$ TU in tea seed oil $(125 \mathrm{mg} / \mathrm{ml})$ were injected in equal parts into the gluteal muscles of seven hypogonadal men. In study II, $1000 \mathrm{mg}$ TU in castor oil $(250 \mathrm{mg} / \mathrm{ml})$ were injected into one gluteal muscle of 14 patients.

Results: In comparison with published data on testosterone enanthate, most widely used for i.m. injections, the kinetic profiles of both TU preparations showed extended half-lives and serum levels not exceeding the upper limit of normal. The castor oil preparation had a longer half-life than TU in tea seed oil ( $33.9 \pm 4.9$ vs $20.9 \pm 6.0$ days (mean \pm s.E.M.) ).

Conclusion: The longer half-life and the smaller injection volume make TU in castor oil a strong candidate for further applications in substitution therapy and in trials for male contraception.
\end{abstract}

European Journal of Endocrinology 140 414-419

\section{Introduction}

Testosterone has been used for substitution therapy for almost six decades. Since the number of patients suffering from hypogonadism and requiring such therapy is relatively small there has not been much drive to develop new testosterone preparations beyond subdermal implants developed in the 1940 s, enanthate and cypionate esters for i.m. injections developed in the $1950 \mathrm{~s}$ and oral testosterone undecanoate (TU) developed in the $1970 \mathrm{~s}$. Although still in use, these preparations are not ideal because of their kinetics, resulting in either supraphysiological or fluctuating serum testosterone levels, and because of the inconvenience of frequent application (for review see reference 1). Only the possibility of new and more widespread indications stimulated a search for alternative application modalities. One result was transdermal systems well suited for long-term substitution because of almost physiological serum testosterone levels (2-4) and because of the possibility for immediate interruption of the treatment if required (e.g. when substituting hypogonadism in senescence) (5). For younger patients and for hormonal male contraception, however, long-acting testosterone preparations continue to be required.

Under the auspices of the WHO, testosterone buciclate was synthesized and tested as an i.m. injection, and in phase I studies showed an extended half-life of
29.5 days (compared with 4.5 days for conventional testosterone enanthate (TE)) (6). However, further development of this ester was hampered by the lack of an industrial partner. We therefore turned to TU prepared for i.m. injection in China and exhibiting an extended half-life in hypogonadal men (7). After confirmation of the long half-life in monkeys (8) we tested the Chinese preparation in hypogonadal men. Since this preparation is based on tea seed oil, uncommon in the Western pharmacopoeia, TU was manufactured for clinical use in castor oil, granting a higher solubility than tea seed oil. Here we present results from phase I studies in hypogonadal men using both the Chinese and the new TU preparation.

\section{Subjects and methods}

\section{Testosterone preparations}

The TU preparation (3-oxoandrost-4-ene-17 $\beta$-yl-undecanoate) used in study I was provided and manufactured by Zhejiang Xian Ju Pharmaceutical Corp. (Zhejiang, People's Republic of China). The steroid was dissolved in tea seed oil at a concentration of $125 \mathrm{mg} / \mathrm{ml}$. TU used in study II was prepared by Jenapharm GmbH \& Co. KG (Jena, Germany). The batch used for all injections had a concentration of $250 \mathrm{mg}$ TU dissolved in $1 \mathrm{ml}$ castor oil. 


\section{Study design and patients}

Study I was performed as a therapeutic trial in agreement with German Drug Law. The protocol of study II was approved by the Ethics Committee of the University of Münster and the State Medical Board. Both studies were conducted at the Institute of Reproductive Medicine in Münster, in agreement with the Declaration of Helsinki and in accordance with Good Clinical Practice. All subjects gave written informed consent.

Seven Caucasian patients $(25-51$ years $)$ with primary $(n=4)$ or secondary $(n=3)$ hypogonadism without additional diseases were enrolled in study I (Table 1). In study II, 14 Caucasian patients (19-45 years) with primary $(n=9)$ or secondary $(n=5)$ hypogonadism without additional diseases participated (Table 1). Three of seven (study I) and 10 of 14 patients (study II) had been treated in the past with i.m. TE and one patient in each study with oral TU before recruitment for the study. In these patients the washout phase before TU injection lasted at least 4 weeks. Three patients in each study were newly diagnosed as hypogonadal and had never been substituted for androgen deficiency before. One patient did not reappear on day 28 of study II or later; his data are only included up to day 21 after TU injection.

In study I, $1000 \mathrm{mg} \mathrm{TU}(2 \times 4 \mathrm{ml}$ on each side $)$ were injected into each of the patient's musculus glutaeus medius on day 0 between 08.00 and $09.00 \mathrm{~h}$. In study II, $1000 \mathrm{mg}$ TU ( $4 \mathrm{ml}$ volume on one injection side) were injected into one of the patient's musculus glutaeus medius at the same time of the day. The blood sampling scheme thereafter was identical in both studies. Blood samples for hormone determinations were drawn between 08.00 and $10.00 \mathrm{~h}$ at two control examinations (days -14 and -7 ), shortly before and $4 \mathrm{~h}$ (only study II) and 1, 2, 3, 5 and 7 days after TU injection, and then weekly up to day 56 (week 8). Blood samples for hormone determinations were separated at $800 \mathrm{~g}$ and stored at $-20{ }^{\circ} \mathrm{C}$ until assayed.

Serum testosterone and estradiol were measured in all samples of both studies, while dihydrotestosterone (DHT), sex hormone-binding globulin (SHBG), luteinizing hormone (LH) and follicle-stimulating hormone (FSH) were determined only in study II.

In study II, clinical chemistry (total protein, albumin, cholesterol, low density lipoprotein (LDL) cholesterol, high density lipoprotein (HDL) cholesterol, triglycerides, glucose, alkaline phosphatase, creatinine, aspartate aminotransferase, alanine aminotransferase, gammaglutamyltranspeptidase, total bilirubin, uric acid, urea nitrogen, sodium, potassium, calcium, chloride and prostate-specific antigen (PSA)) and hematology (red cell count, hemoglobin, hematocrit, white cell count, platelet count, prothrombin time (Quick test) and partial thromboplastin time) were performed at the control examinations, shortly before injection of the testosterone ester, and then weekly up to the end of the study. Urinalysis was performed before TU injection and at the final examination of study II. Blood and urine samples were taken after a $10 \mathrm{~h}$ fast.

Table 1 Anthropomorphic and clinical data of patients.

\begin{tabular}{|c|c|c|c|c|c|c|}
\hline & $\begin{array}{c}\text { Age } \\
\text { (years) }\end{array}$ & $\begin{array}{l}\text { Height } \\
\text { (cm) }\end{array}$ & $\begin{array}{l}\text { Weight } \\
\quad(\mathrm{kg})\end{array}$ & $\begin{array}{c}\text { BMI* }^{*} \\
\left(\mathrm{~kg} / \mathrm{m}^{2}\right)\end{array}$ & $\begin{array}{c}\text { Type of } \\
\text { hypogonadism }\end{array}$ & $\begin{array}{c}\text { Previous testosterone } \\
\text { treatment }\end{array}$ \\
\hline \multicolumn{7}{|c|}{ Study I } \\
\hline 1 & 51 & 175 & 80.0 & 26.1 & Primary & TU p.o. \\
\hline 2 & 37 & 187 & 74.6 & 21.3 & Secondary & TE i.m. \\
\hline 3 & 26 & 182 & 66.0 & 19.9 & Secondary & Without \\
\hline 4 & 29 & 178 & 62.5 & 19.7 & Secondary & TE i.m. \\
\hline 5 & 25 & 172 & 61.5 & 20.8 & Primary & Without \\
\hline 6 & 35 & 184 & 85.0 & 25.1 & Primary & Without \\
\hline 7 & 40 & 179 & 93.5 & 29.2 & Primary & TE i.m. \\
\hline \multicolumn{7}{|c|}{ Study II } \\
\hline 1 & 42 & 179 & 99.1 & 30.9 & Primary & TE i.m. \\
\hline 2 & 20 & 161 & 55.2 & 21.3 & Primary & TE i.m. \\
\hline 3 & 21 & 179 & 96.0 & 30.0 & Primary & Without \\
\hline 4 & 34 & 191 & 82.2 & 22.5 & Primary & TE i.m. \\
\hline 5 & 19 & 178 & 94.7 & 29.9 & Primary & TE i.m. \\
\hline 6 & 36 & 182 & 73.0 & 22.0 & Primary & TE i.m. \\
\hline 7 & 31 & 198 & 84.6 & 21.6 & Primary & TE i.m. \\
\hline 8 & 39 & 188 & 79.5 & 22.5 & Secondary & TE i.m. \\
\hline 9 & 38 & 176 & 95.1 & 30.7 & Secondary & TE i.m. \\
\hline 10 & 22 & 171 & 67.0 & 22.9 & Secondary & TE i.m. \\
\hline 11 & 26 & 176 & 102.0 & 32.9 & Primary & TU p.o. \\
\hline 12 & 19 & 186 & 72.1 & 20.8 & Primary & Without \\
\hline 13 & 35 & 190 & 114.4 & 31.7 & Secondary & TE i.m. \\
\hline 14 & 45 & 182 & 70.0 & 21.1 & Secondary & Without \\
\hline
\end{tabular}

* BMI = body mass index. 


\section{Immunoassays}

Testosterone and DHT were separated in extracted serum samples by HPLC before measurement by RIAs. The detection limits for testosterone and DHT were 0.28 and $0.14 \mathrm{nmol} / \mathrm{l}$ respectively. The intra- and interassay coefficients of variation for testosterone were 6.6 and $9.8 \%$ respectively, and for DHT 7.2 and $12.3 \%$ respectively. In our laboratory the normal range for testosterone after separation by HPLC is $10-35 \mathrm{nmol} / \mathrm{l}$ and the upper normal limit for DHT is $2.9 \mathrm{nmol} / \mathrm{l}$. Estradiol was measured by RIA (Sorin Biomedica, Saluggia, Italy). The detection limit for estradiol was $37 \mathrm{pmol} / \mathrm{l}$. The intra- and interassay coefficients of variation for estradiol were 6.8 and $8.2 \%$ respectively. The upper normal limit for estradiol is $250 \mathrm{pmol} / \mathrm{l}$.

Serum LH, FSH, SHBG and PSA were determined by specific fluoroimmunoassays (Pharmacia $\mathrm{GmbH}$, Freiburg, Germany). The lower detection limits for FSH, LH and SHBG were $0.25 \mathrm{IU} / \mathrm{l}, 0.12 \mathrm{IU} / \mathrm{l}$ and $6.3 \mathrm{nmol} / \mathrm{l}$ respectively. The intra- and interassay coefficients of variation for LH were 4.5 and $6.4 \%$ respectively, for FSH 3.7 and $5.4 \%$ respectively, and for SHBG 4.8 and $7.4 \%$ respectively. In our laboratory the normal range for $\mathrm{LH}$ is $2-10 \mathrm{IU} / \mathrm{l}$, for $\mathrm{FSH}$ $1-7 \mathrm{IU} / \mathrm{l}$ and for SHBG $11-71 \mathrm{nmol} / \mathrm{l}$. The lower detection limit for PSA is $0.5 \mu \mathrm{g} / \mathrm{l}$ and the upper reference limit is $4 \mu \mathrm{g} / \mathrm{l}$. Not detected PSA levels were defined as $0.25 \mu \mathrm{g} / \mathrm{l}$. The intra- and interassay coefficients of variation for PSA were 5.8 and $11.7 \%$ respectively. All analytical methods were executed and documented in accordance with the principles of Good Laboratory Practice.

\section{Pharmacokinetic evaluations and statistics}

For evaluation of TU pharmacokinetics and for removal of between-subject variations in basal endogenous testosterone the increments from the subject's own baseline testosterone values were analyzed. Analysis included AUC (area under the concentration versus time curve, calculated by the trapezoidal method), $\mathrm{C}_{\max }$ (concentration maximum, calculated from the individual data), $t_{\max }$ (time of reaching $C_{\max }$, calculated from the individual data), and $t_{1 / 2} \beta$ (terminal elimination half-life) (9).

Significant variations over time of any variable were evaluated by ANOVA for repeated measures. In case of a general effect over time, values at single time points were analyzed in more detail by comparison with the baseline value before injection using the Duncan multiple comparison test for repeated measures. When necessary, analysis was performed on logarithmically transformed data. $P$ values $<0.05$ were considered significant. Unless otherwise stated, results are given as mean \pm S.E.M.

\section{Results}

The i.m. injections of $1000 \mathrm{mg}$ TU into either one or both gluteal regions were well tolerated by all 21 hypogonadal patients included in the studies. No serious adverse effects were observed. In study II, detailed weekly diaries of 4 out of 14 patients revealed some discomfort at the injection site persisting not longer than 1 week after injection; one patient reported some pain at the injection site on day 14 . No patient reported the injections to be more painful or inconvenient than former i.m. injections. One patient reported transient testicular pain at day 28. Clinical examinations revealed no new occurrence of gynecomastia nor any enlargement or soreness of the liver; one patient showed sporadic signs of acne 2 and 5 weeks after TU injection. No patient discontinued treatment because of side-effects.

\section{Testosterone and DHT}

In study I, injections of TU in tea seed oil increased testosterone serum levels in a time-dependent pattern (Fig. 1, upper panel) $(P<0.001)$. One day after injection serum levels of testosterone rose from basal levels of $4.8 \pm 0.9$ to levels of $14.9 \pm 1.4 \mathrm{nmol} / \mathrm{l}$ in the normal

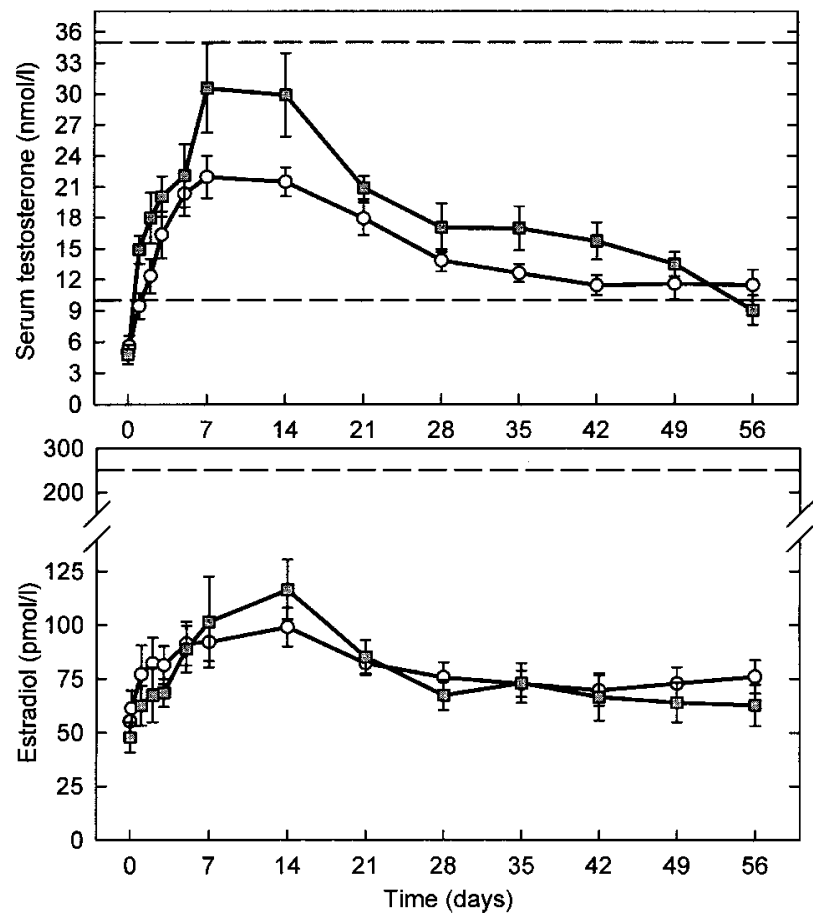

Figure 1 Serum concentrations (mean \pm S.E.M.) of testosterone (upper panel) and estradiol (lower panel) after single dose i.m. injections of $1000 \mathrm{mg}$ TU in tea seed oil in 7 hypogonadal men (study I, squares) or castor oil in 14 hypogonadal men (study II, circles). Broken lines indicate normal range of testosterone and upper normal limit of estradiol. 
Table 2 Pharmacokinetic data (mean \pm S.E.M.) of the two TU preparations after i.m. injection of $1000 \mathrm{mg}$ TU in comparison with previously published kinetic data from TE and testosterone buciclate (TB).

\begin{tabular}{|c|c|c|c|c|c|}
\hline Preparation/concentration & $\begin{array}{c}\text { Total dose } \\
\text { injected (mg) }\end{array}$ & $\begin{array}{c}\text { AUC } \\
(\mathrm{nmol} \times \text { days/l) }\end{array}$ & $\underset{(\mathrm{nmol} / \mathrm{l})}{\mathbf{C}_{\max }}$ & $\begin{array}{c}\mathbf{t}_{\max } \\
\text { (days) }\end{array}$ & $\begin{array}{c}\mathbf{t}_{1 / 2} \\
\text { (days) }\end{array}$ \\
\hline TU 125 mg/ml (tea seed oil) & 1000 & $\mathrm{AUC}_{(0-8}$ weeks $) 825 \pm 93$ & $30.1 \pm 5.5$ & $13.0 \pm 3.7$ & $20.9 \pm 6.0$ \\
\hline TU $250 \mathrm{mg} / \mathrm{ml}$ (castor oil) & 1000 & $\mathrm{AUC}_{(0-8 \text { weeks })} 534 \pm 49$ & $19.3 \pm 2.1$ & $11.4 \pm 1.5$ & $33.9 \pm 4.9$ \\
\hline TB $200 \mathrm{mg} / \mathrm{ml}$ (aqueous suspension)* & 600 & $\mathrm{AUC}_{(0-16 \text { weeks })} 377 \pm 68$ & $6.7 \pm 1.2$ & $25.8 \pm 8.2$ & $29.5 \pm 3.9$ \\
\hline TE $250 \mathrm{mg} / \mathrm{ml}$ (castor oil)† & 250 & $\mathrm{AUC}_{(0-3 \text { weeks })} 376$ & 39.4 & 10 & 4.5 \\
\hline
\end{tabular}

* Data from reference (6).

† Data from reference (11) as re-analysed from reference (18).

range. $C_{\max }$ were seen between day 7 (30.5 \pm $4.3 \mathrm{nmol} / \mathrm{l})$ and $14(29.9 \pm 4.0 \mathrm{nmol} / \mathrm{l})$. In three of seven patients, individual values exceeded the normal range with $C_{\text {max }}$ of $52.6 \mathrm{nmol} / \mathrm{l}$ in one patient 14 days after injection. Mean testosterone levels remained in the normal range up to week 7 and were back in the hypogonadal range 8 weeks after injection $(9.1 \pm$ $1.4 \mathrm{nmol} / \mathrm{l})$. Pharmacokinetic analysis revealed a $\mathrm{t}_{1 / 2} \beta$ of $20.9 \pm 6.0$ days (Table 2 ).

In study II, after injection of $1000 \mathrm{mg}$ TU in castor oil, serum levels of testosterone rose from basal levels of $5.0 \pm 0.8$ to normal levels of $12.3 \pm 1.7 \mathrm{nmol} / \mathrm{l} 2$ days after injection (Fig. 1, upper panel) $(P<0.001)$. $C_{\max }$ were seen between day $7(22.0 \pm 2.0 \mathrm{nmol} / \mathrm{l})$ and $14(21.5 \pm 1.4 \mathrm{nmol} / \mathrm{l})$. Individual values exceeded the normal range at days 3,5 and 7 with $C_{\max }$ of $40.8 \mathrm{nmol} / \mathrm{l} 3$ days after injection in only 1 of 14 patients. Mean levels in the lower normal range and significantly higher compared with baseline values were maintained up to week 8 after injection $(11.5 \pm$ $1.5 \mathrm{nmol} / \mathrm{l})$. Pharmacokinetic analysis revealed a $\mathrm{t}_{1 / 2} \beta$ of 33.9 \pm 4.9 days (Table 2).

In study II, mean serum concentrations of DHT increased significantly after TU injection $(P<0.001)$ (Fig. 2, upper panel). $C_{\max }$ were seen between day 7 $(1.4 \pm 0.4 \mathrm{nmol} / \mathrm{l})$ and $14(1.4 \pm 0.2 \mathrm{nmol} / \mathrm{l})$. In 2 of the 14 patients, individual values of DHT exceeded the normal range: at day 7 in one patient $(3.09 \mathrm{nmol} / \mathrm{l})$ and from day 3 to 14 in the other $\left(\mathrm{C}_{\max } 4.6 \mathrm{nmol} / \mathrm{l}\right)$. Serum concentrations of DHT remained significantly elevated compared with baseline up to day 35 .

\section{Estrogens and SHBG}

In study I, TU administration in tea seed oil increased serum estradiol significantly $(P<0.001)$ from $47.8 \pm$ $7.0 \mathrm{pmol} / \mathrm{l}$ to $\mathrm{a} \mathrm{C}_{\max }$ of $116.4 \pm 13.9 \mathrm{pmol} / \mathrm{l} 14$ days after injection (Fig. 1, lower panel). All individual values remained within the normal range.

In study II, administration of TU in castor oil increased serum concentrations of estradiol significantly $(P<0.001)$ from $55.3 \pm 6.4 \mathrm{pmol} / \mathrm{l}$ to a $C_{\max }$ of $99.0 \pm 9.0 \mathrm{pmol} / \mathrm{l} 14$ days after injection (Fig. 1, lower panel). All individual values remained in the normal range throughout study II.
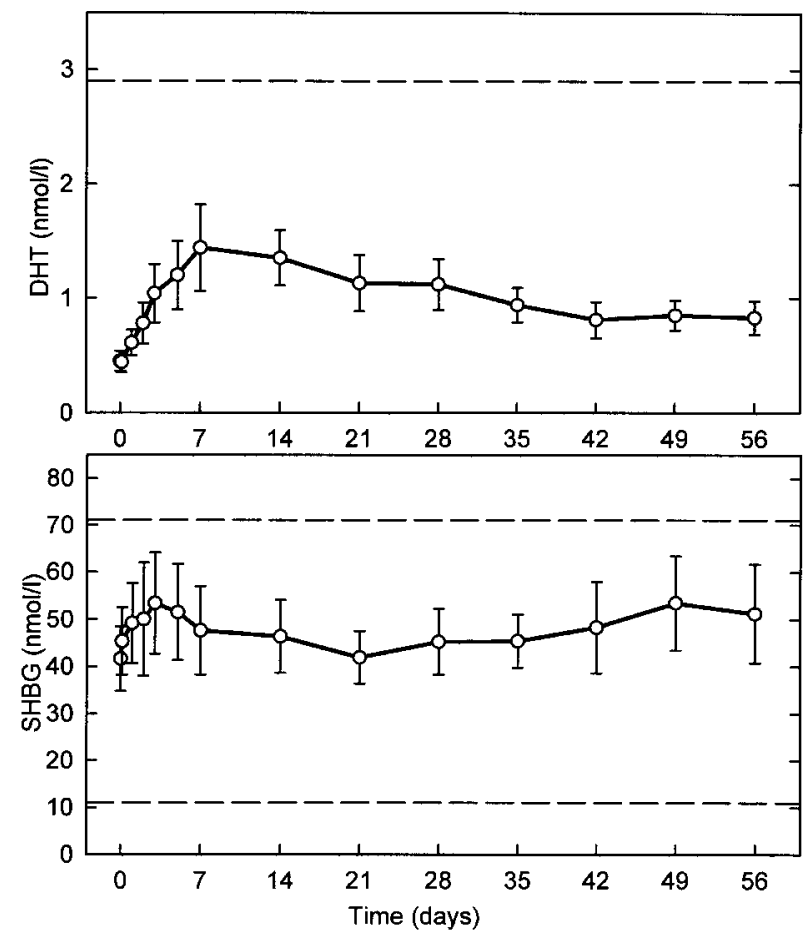

Figure 2 Serum concentrations (mean \pm S.E.M.) of DHT (upper panel) and SHBG (lower panel) after single dose i.m. injections of $1000 \mathrm{mg}$ TU in castor oil in 14 hypogonadal men (study II). Broken lines indicate upper normal limit of DHT and normal range of SHBG.

A small, but marginally significant increase of SHBG $(P<0.01)$ compared with baseline was seen on days 1 , 2 and 3 after TU injection in study II. In general, SHBG levels remained constant throughout the study (Fig. 2, lower panel).

\section{Gonadotropins}

In the nine patients of study II with primary hypogonadism and elevated gonadotropins, LH was significantly suppressed from a baseline of $21.5 \pm 2.5$ to $14.3 \pm 3.5 \mathrm{IU} / \mathrm{l}$ at day $35(P<0.005)$ (Fig. 3, upper panel). FSH serum concentrations were only marginally, but significantly, lowered by TU administration 

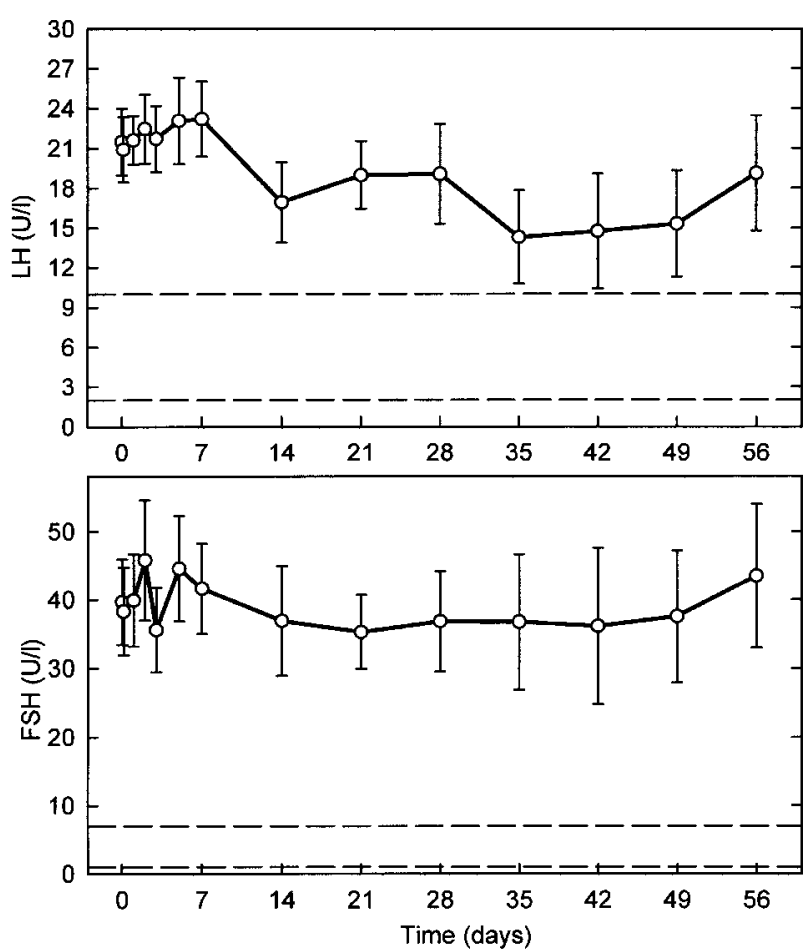

Figure 3 Serum concentrations (mean \pm S.E.M.) of LH (upper panel) and FSH (lower panel) after single dose i.m. injections of $1000 \mathrm{mg}$ TU in castor oil in nine men with primary hypogonadism (study II). Broken lines indicate normal ranges of $\mathrm{LH}$ and $\mathrm{FSH}$.

from $39.7 \pm 6.2$ to a nadir of $35.3 \pm 5.4 \mathrm{U} / \mathrm{l}$ at study day $21(P=0.017)$ (Fig. 3, lower panel).

\section{Body weight and blood pressure}

Body weight as well as systolic and diastolic blood pressure did not change significantly throughout study II.

\section{Clinical chemistry and hematology}

No significant changes in clinical chemistry, including cholesterol, HDL cholesterol, LDL cholesterol and liver function tests were observed throughout study II. Hemoglobin, erythrocytes and hematocrit were not different from baseline. No significant change was seen in leukocyte or platelet counts throughout the study. No significant change was seen in blood coagulation as assessed by partial thromboplastin time and prothrombin time.

Serum levels of PSA increased significantly $(P<0.001)$ from baseline of $0.33 \pm 0.06$ to $0.56 \pm$ $0.07 \mu \mathrm{g} / \mathrm{l}$ at day 28 . Levels at day 56 of $0.48 \pm 0.08 \mu \mathrm{g} / \mathrm{l}$ were no longer statistically different from baseline. All individual PSA values remained well within the normal range $\left(C_{\max } 1.6 \mu \mathrm{g} / \mathrm{l}\right.$ in one patient at day 35$)$.

\section{Discussion}

Intramuscularly injected TE is the most widely used testosterone preparation when depot effects are required, e.g. for substitution of hypogonadism (1) or in trials for hormonal male contraception (10). However, after injection of the commonly administered dose of 200 or $250 \mathrm{mg}$, TE has the disadvantage that it produces supraphysiological serum testosterone levels during the days immediately following administration with a slow decline to the lower limit of normal following within 10-14 days (11). Patients dislike these swings in serum testosterone levels, which they experience as ups and downs in vigour, mood and sexual activity. Other testosterone esters in clinical use such as testosterone cypionate or cyclohexanecarboxylate show pharmacokinetic profiles almost identical to that of TE $(12,13)$, so that these preparations offer no therapeutic advantage.

Although the current study deals with a much higher dose of testosterone than administered in previous studies, TU does not result in supranormal serum testosterone levels, but in much prolonged action. Extrapolating from single-dose kinetics it appears that upon repeated injections of $1000 \mathrm{mg}$, injection intervals of $6-10$ weeks will be possible. The prolonged intervals and the normal serum testosterone levels throughout the injection-free period would be welcomed by the hypogonadal patient requiring substitution as well as by the eugonadal male seeking contraceptive protection.

Although different routes of administration may yield different toxicological profiles for the same drug, the lack of serious side-effects from TU administered orally at doses of 80-160 mg/day over many years (14) gives reason to assume that TU applied i.m. might also be well tolerated. Indeed, no untoward side-effects have been reported from i.m. use in China $(7,15)$. The reason for the prolonged half-life of $\mathrm{TU}$ in comparison with TE is the longer aliphatic, and thus more hydrophobic, side-chain, comprising 11 instead of 7 carbon atoms. Similarly, testosterone buciclate has a prolonged duration of action, which is caused by the hydrophobic benzol ring incorporated into the side-chain.

Recently, it was shown in Chinese men that i.m. injection of $1000 \mathrm{mg}$ TU dissolved in tea seed oil at a concentration of $125 \mathrm{mg} / \mathrm{ml}$ has a similar pharmacokinetic profile with a $t_{1 / 2} \beta$ of $23.7 \pm 2.7$ days compared with our study with the tea seed oil preparation in Caucasian men (15). The longer duration of action of TU in castor oil compared with TU in tea seed oil could be due to the properties of the oils, the different concentrations $(125$ vs $250 \mathrm{mg} / \mathrm{ml})$ and injection volumes (4 vs $8 \mathrm{ml}$ ), as well as unilateral vs bilateral gluteal application. It is conceivable that the larger surface of the depot produced by $2 \times 4 \mathrm{ml}$ injections leads to a slightly faster release of the testosterone 
ester, resulting in higher $C_{\max }$ values and a slightly shorter half-life than the single $4 \mathrm{ml}$ depot with more concentrated TU. It has been shown that different physico-chemical properties of the oil used as vehicle (16), as well as different injection volumes (17), may influence the kinetics of administered androgens.

In summary, i.m. TU in castor oil has a considerably longer half-life than conventional TE, producing serum levels in the normal range over 6 weeks. These properties make it an attractive candidate for substitution therapy as well as for use in male contraception.

\section{Acknowledgements}

We are grateful to Karin Brunswicker and Nicole Terwort for technical assistance. The study was in part supported by the German Federal Health Ministry, Bonn and the Deutsche Forschungsgemeinschaft, Bonn. We thank Dr Fricke, Jenapharm GmbH \& Co. KG for the supply of the TU ampoules. We are grateful to Susan Nieschlag for language editing of the manuscript.

\section{References}

1 Nieschlag E \& Behre HM. Pharmacology and clinical uses of testosterone. In Testosterone - Action, Deficiency, Substitution, edn 2, pp 293-328. Eds E Nieschlag \& HM Behre. Berlin, Heidelberg, New York: Springer-Verlag, 1998.

2 Atkinson LE, Chang Y-L \& Snyder JP. Long-term experience with testosterone replacement through scrotal skin. In Testosterone Action, Deficiency, Substitution, edn 2, pp 364-388. Eds E Nieschlag \& HM Behre. Berlin, Heidelberg, New York: Springer-Verlag, 1998.

3 Meikle AW. A permeation-enhanced non-scrotal testosterone transdermal system for the treatment of male hypogonadism. In Testosterone - Action, Deficiency, Substitution, edn 2, pp 389-422. Eds E Nieschlag \& HM Behre. Berlin, Heidelberg, New York: Springer-Verlag, 1998.

4 Behre HM, von Eckardstein S, Kliesch S \& Nieschlag E. Long-term substitution therapy of hypogonadal men with transscrotal testosterone over seven to ten years. Clinical Endocrinology 1999 (In Press).

5 Nieschlag E. If testosterone, which testosterone? Which androgen regimen should be used for supplementation in older men? Formulation, dosing, and monitoring issues. Therapeutic controversy VII. Journal of Clinical Endocrinology and Metabolism 1998 83 3443-3445.
6 Behre HM \& Nieschlag E. Testosterone buciclate (20 Aet-1) in hypogonadal men: pharmacokinetics and pharmacodynamics of the new long-acting androgen ester. Journal of Clinical Endocrinology and Metabolism 199275 1204-1210.

7 Wang LZ. The therapeutic effect of domestically produced testosterone undecanoate in Klinefelter's syndrome. New Drugs and Markets 19918 28-32.

8 Partsch C-J. Weinbauer GF, Fang R \& Nieschlag E. Injectable testosterone undecanoate has more favourable pharmacokinetics and pharmacodynamics than testosterone enanthate. European Journal of Endocrinology 1995132 514-519.

9 Gibaldi M \& Perrier D. Pharmacokinetics. New York: Marcel Dekker, 1992.

10 World Health Organization Task Force on Methods for the Regulation of Male Fertility. Contraceptive efficacy of testosterone-induced azoospermia and oligozoospermia in normal men. Fertility and Sterility $199665821-829$.

11 Behre HM \& Nieschlag E. 1998 Comparative pharmacokinetics of testosterone esters. In Testosterone - Action, Deficiency, Substitution, edn 2, pp 329-348. Eds E Nieschlag \& HM Behre. Berlin, Heidelberg, New York: Springer-Verlag, 1998.

12 Schulte-Beerbühl M \& Nieschlag E. Comparison of testosterone, dihydrotestosterone, luteinizing hormone, and follicle-stimulating hormone in serum after injection of testosterone enanthate or testosterone cypionate. Fertility and Sterility $198033201-$ 203.

13 Schürmeyer T \& Nieschlag E. Comparative pharmacokinetics of testosterone enanthate and testosterone cyclohexanecarboxylate as assessed by serum and salivary testosterone levels in normal men. International Journal of Andrology 19847 181-187.

14 Gooren LJG. A ten year safety study of the oral androgen testosterone-undecanoate. Journal of Andrology 199415 212-215.

15 Zhang GY, Gu YQ, Wang XH, Cui YG \& Bremner WJ. A pharmacokinetic study of injectable testosterone undecanoate in hypogonadal men. Journal of Andrology 199819 761-768.

16 Minto CF, Howe C, Wishart S, Conway AJ \& Handelsman DJ. Pharmacokinetics and pharmacodynamics of nandrolone esters in oil vehicle: effects of ester, injection site and injection volume. Journal of Pharmacology and Experimental Therapeutics 1997281 93-102.

17 Gerrity M, Freund M, Peterson RN \& Falvo RE. The physiologic effects of testosterone in hydrogenated soybean oil vehicle as compared with free testosterone, testosterone propionate, and testosterone enanthate in a conventional oil vehicle. Journal of Andrology $19823221-226$.

18 Nieschlag E, Cüppers HJ, Wiegelmann W \& Wickings EJ. Bioavailability and LH-suppressing effect of different testosterone preparations in normal and hypogonadal men. Hormone Research $19767138-145$.

Received 20 October 1998

Accepted 2 February 1999 